\title{
Numerical prediction of sporadic E layer occurrence using GAIA
}

\author{
Hiroyuki Shinagawa ${ }^{1 *}\left(\mathbb{D}\right.$, Chihiro Tao $^{1}$, Hidekatsu $\mathrm{Jin}^{1}$, Yasunobu Miyoshi ${ }^{2}$ and Hitoshi Fujiwara ${ }^{3}$
}

\begin{abstract}
A sporadic E layer has significant influence on radio communications and broadcasting, and predicting the occurrence of sporadic $E$ layers is one of the most important issues in space weather forecast. While sporadic $E$ layer occurrence and the magnitude of the critical sporadic E frequency (foEs) have clear seasonal variations, significant day-to-day variations as well as regional and temporal variations also occur. Because of the highly complex behavior of sporadic E layers, the prediction of sporadic E layer occurrence has been one of the most difficult issues in space weather forecast. To explore the possibility of numerically predicting sporadic E layer occurrence, we employed the whole atmosphere-ionosphere coupled model GAIA, examining parameters related to the formation of sporadic E layer such as vertical ions velocities and vertical ion convergences at different altitudes between 90 and $150 \mathrm{~km}$. Those parameters in GAIA were compared with the observed foEs data obtained by ionosonde observations in Japan. Although the agreement is not very good in the present version of GAIA, the results suggest a possibility that sporadic E layer occurrence can be numerically predicted using the parameters derived from GAIA. We have recently developed a real-time GAIA simulation system that can predict atmosphere-ionosphere conditions for a few days ahead. We present an experimental prediction scheme and a preliminary result for predicting sporadic E layer occurrence.
\end{abstract}

Keywords: Sporadic E layer, Wind shear, Occurrence, Prediction, GAIA, Model, Vertical ion convergence

\section{Introduction}

Sporadic E (Es) layers are narrow layers with high electron densities consisting mainly of metallic ions. These layers appear sporadically in the region predominantly at altitudes between 90 and $120 \mathrm{~km}$. Among the many kinds of space weather disturbances, Es layers are one of the most important phenomena because they significantly affect radio communication and broadcast systems with high-frequency (HF) and very high-frequency (VHF) radio waves. In addition, recent studies also suggest that Es layers have a potential impact on air-navigation systems, which use VHF radio waves (Sakai et al. 2019).

At the National Institute of Information and Communications Technology (NICT), Es layers as well as other

\footnotetext{
*Correspondence: sinagawa@nict.go.jp

'Space Environment Laboratory, Applied Electromagnetic Research Institute, National Institute of Information and Communications

Technology, Tokyo 184-8795, Japan

Full list of author information is available at the end of the article
}

ionospheric disturbances above Japan are monitored with four ionosonde stations in Japan: Wakkanai $\left(45.16^{\circ} \mathrm{N}\right.$, $\left.141.75^{\circ} \mathrm{E}\right)$, Kokubunji $\left(35.71^{\circ} \mathrm{N}, 139.49^{\circ} \mathrm{E}\right)$, Yamagawa $\left(31.20^{\circ} \mathrm{N}, 130.62^{\circ} \mathrm{E}\right)$, and Okinawa $\left(26.68^{\circ} \mathrm{N}, 128.15^{\circ} \mathrm{E}\right)$. The critical sporadic E frequency $f o E s$, which is an index of the intensity of Es layers, is derived from the ionosonde data. In the space weather forecast at NICT, a foEs larger than $8 \mathrm{MHz}$ is the criterion for "Es layer occurrence". On the basis of this criterion, the Space Weather Forecast Center at NICT issues an Es layer forecast along with forecasts of other space weather disturbances (http://swc. nict.go.jp/en/).

The observed ionosonde data are stored in a database that is open to the public and is also utilized for many kinds of research on the ionosphere. Characteristic ionospheric parameters such as $f o F_{2}, h^{\prime} F_{2}$, and $f_{o} E s$ derived from the data are categorized into two types of parameters: manually scaled parameters and automatically scaled parameters. The automatically scaled parameters are automatically generated with ionogram scaling

\section{Springer Open}

(c) The Author(s) 2021. This article is licensed under a Creative Commons Attribution 4.0 International License, which permits use, sharing, adaptation, distribution and reproduction in any medium or format, as long as you give appropriate credit to the original author(s) and the source, provide a link to the Creative Commons licence, and indicate if changes were made. The images or other third party material in this article are included in the article's Creative Commons licence, unless indicated otherwise in a credit line to the material. If material is not included in the article's Creative Commons licence and your intended use is not permitted by statutory regulation or exceeds the permitted use, you will need to obtain permission directly from the copyright holder. To view a copy of this licence, visit http://creativeco mmons.org/licenses/by/4.0/. 
algorithms. This system works in real time, but errors occur occasionally owing to the detection of noise signals. The manually scaled parameters are obtained manually and are more accurate than automatically scaled parameters, but are not available in real time. Therefore, in our present study, manually scaled parameters obtained in the past are used for comparisons with GAIA-derived parameters.

The results of a number of studies of Es layers have suggested that a vertical neutral wind shear in the lower thermosphere plays an important role in Es layer formation. The mechanism of ion convergence driven by the neutral wind shear called "wind shear theory" has been confirmed by a number of theoretical and modeling studies (MacLeod 1966; Kato et al. 1972; Mathews and Bekeny 1979; Earle et al. 1998; Arras et al. 2008; Christakis et al. 2009; Chu et al. 2011, 2014; Haldoupis 2012; Yeh et al. 2014; Chu and Yu 2017; Shinagawa et al. 2017). Chu et al. (2014) employed the empirical neutral wind model HWM07 (Drob et al. 2008) to simulate an Es layer. They found that the basic behavior of Es layers is highly coincident with the neutral wind shear, and that the diurnal and seasonal variations in Es layer occurrence can be mainly attributed to variations in the neutral wind shear. While the basic formation processes of Es layers are reproduced by numerical models fairly well, the prediction of Es layer occurrence is still a challenging task, mainly because of the complex behavior of the neutral wind in the lower thermosphere. Therefore, no attempts have been made to numerically predict the occurrence of Es layers.

To explore the possibility of Es layer prediction, we investigated parameters related to Es layer formation such as vertical ions velocities and vertical ion convergences at different altitudes between 90 and $150 \mathrm{~km}$ using simulation data obtained from the whole atmosphereionosphere coupled model GAIA (Jin et al. 2012; Miyoshi et al. 2012).

Then we compared those parameters with foEs data obtained from the ionosonde observations at NICT's stations. It was found that the vertical ion convergence $(V I C)$, especially VIC at $120 \mathrm{~km}$ altitude $\left(V I C_{120}\right)$, has the best correlation with $f o E s$ so far, suggesting that $V I C_{120}$ derived from GAIA simulations can be used as practical indices for the prediction of Es layer occurrence. Preliminary results of predictions of Es layer occurrence and values of $f o E s$ derived from the GAIA simulation data are presented.

\section{Method of analysis}

We analyzed foEs data obtained from the NICT ionosonde observations and simulation data produced by GAIA. An example of observed foEs data (manually scaled $f o E s$ ), which was derived from ionosonde data obtained at Kokubunji in 2009, is shown in Fig. 1. The day of the year in the plot is in JST (Japan Standard Time $=\mathrm{UT}+9 \mathrm{~h}$ ). The observed foEs exhibits clear seasonal variations: larger in summer and smaller in other seasons with occasional enhancement in winter (Fig. 1a). The seasonal variations in Es layer occurrence and in $f o E s$ have been observed in a number of observational studies (e.g., Haldoupis et al. 2007; Christakis et al. 2009; $\mathrm{Chu}$ et al. 2014; Yeh et al. 2014). Figure 1b shows foEs between days 160 and 190 in Fig. 1a, indicating that foEs also has significant day-to-day variations as well as hourly variations.

The GAIA model used in the present analysis is basically the same as the one used by Shinagawa et al. (2017). For the neutral atmosphere part of GAIA, the horizontal resolutions are $2.8^{\circ}$ in longitude and latitude and the vertical resolution is 0.2 scale height. The ionosphere part of GAIA employs a finite difference scheme with a spatial grid of $2.5^{\circ}$ longitude by $1^{\circ}$ latitude horizontally, and the vertical grid interval is $10 \mathrm{~km}$ below $600 \mathrm{~km}$. At altitudes higher than $600 \mathrm{~km}$, the grid size gradually increases up to the upper boundary of $3000 \mathrm{~km}$.

Data from the JRA-55 meteorological reanalysis (Kobayashi et al. 2015; Harada et al. 2016) are incorporated in the lower atmosphere by a nudging method (Jin et al. 2012). The $F_{10.7}$ index and the geomagnetic field model (IGRF) are taken from the NOAA National Centers for Environmental Information (NCEI) database (https:// www.ngdc.noaa.gov). In the present analysis, a quiet magnetospheric condition with a constant cross-polarcap potential of $30 \mathrm{kV}$ is assumed (Fujiwara and Miyoshi 2006). Thus, effects of magnetic storms are not included in the simulation data. This is a reasonable assumption because Es layers are little affected by magnetic disturbances (Whitehead 1989).

The velocity $w_{\mathrm{i}}$ of vertical ion drift driven by vertical shear of horizontal neutral wind can be expressed as follows (Mathews 1998):

$$
w_{\mathrm{i}}=\frac{V \cos I \sin I+\left(\frac{v_{\mathrm{i}}}{\omega_{\mathrm{i}}}\right) U \cos I}{1+\left(\frac{v_{\mathrm{i}}}{\omega_{\mathrm{i}}}\right)^{2}},
$$

where $v_{\mathrm{i}}$ is the collision frequency of ions relative to neutral species, $\omega_{\mathrm{i}}$ is the ion gyro frequency, $U$ is the eastward neutral wind velocity, $V$ is the southward neutral wind velocity, and $I$ is the magnetic dip angle. The only ion species-dependent term is $\left(v_{\text {in }} / \omega_{\mathrm{i}}\right)$ in Eq. (1), and it has weak dependence on the mass of ion species. The ion used in our analysis is assumed to be $\mathrm{NO}^{+}$(atomic mass $=30.0$ ), which is a background ion. Using metallic ions such as $\mathrm{Fe}^{+}$(atomic mass $=55.9$ ) and $\mathrm{Mg}^{+}$(atomic mass $=24.3$ ) would result in somewhat different number 


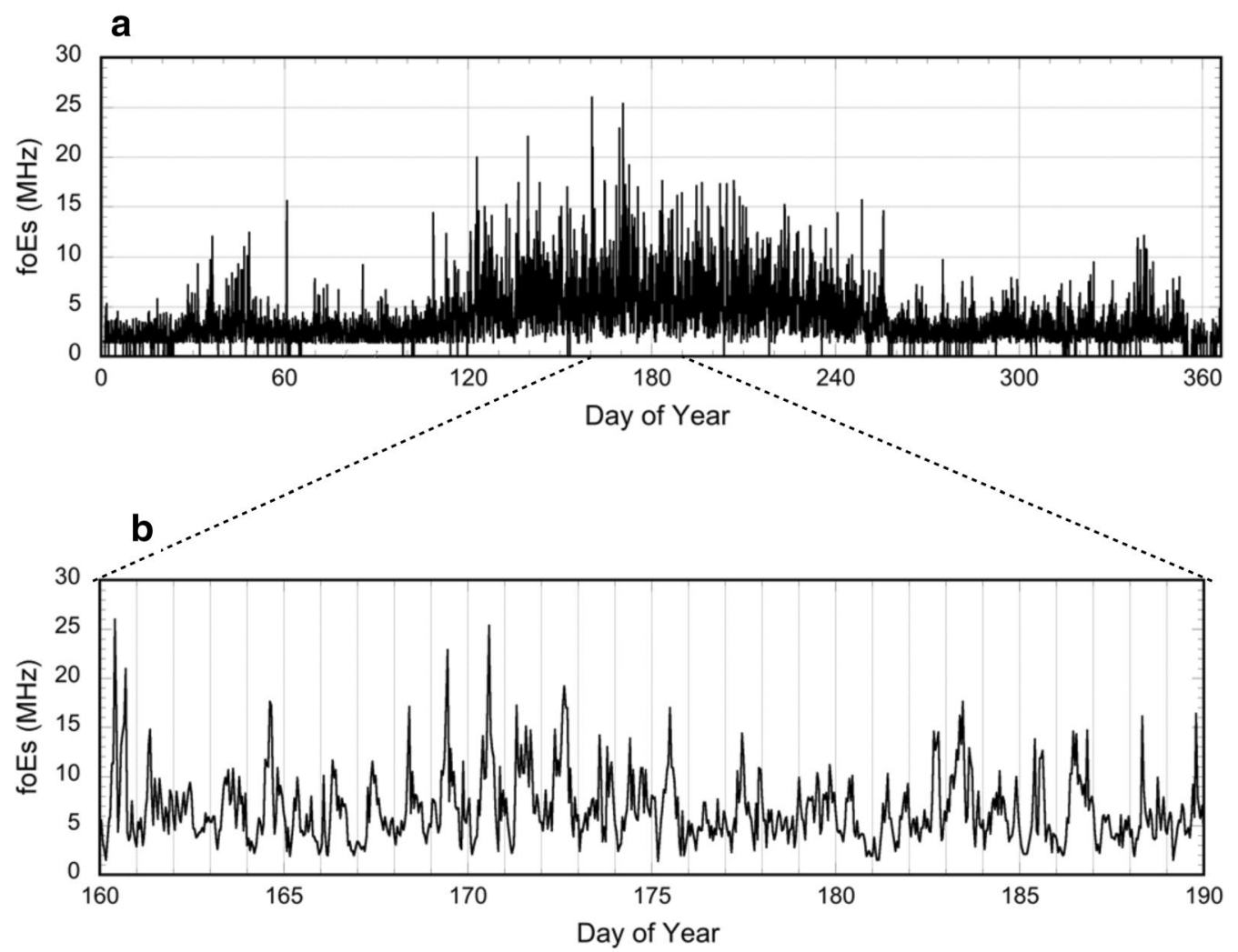

Fig. 1 Observed foEs data at Kokubunji in 2009. foEs data are obtained by the ionosonde observation at Kokubunji in 2009 for a the entire year and b the days from 160 to 190. The day of year is in Japan Standard Time (UT+9 h)

(about 10\% difference). This is considered to be insignificant because $\left(v_{\text {in }} / \omega_{\mathrm{i}}\right)$ is proportional to the neutral density, which changes rapidly with altitude.

Using Eq. (1), the vertical ion convergence VIC can be obtained from

$$
V I C=-\frac{\partial w_{\mathrm{i}}}{\partial z}
$$

The values of VIC are compared with the observed foEs obtained by the ionosondes operated at NICT's stations. In our analyses, we used 1-h $f o E s$ data at Kokubunji for the comparisons of the observed foEs and VIC. Note that the "daily" values are those for $0-24 \mathrm{~h}$ in JST.

To investigate the seasonal and day-to-day variations in the observed $f_{0 E s}$ and calculated VIC and the relationship between them, we first compare $f o E s$ and $V I C$ for (1) daily average values, (2) daily maximum values, and (3) 1 - $\mathrm{h}$ values. Then, a method of estimating daily maximums of $f o E s$ from GAIA data is presented. Finally, we compare "predicted" foEs derived from GAIA with $f o E s$ observed at Okinawa in 2019. We used foEs data from Okinawa because the manually scaled data from Kokubunji were not available at the time of this study.

\section{Results}

Comparison of daily average foEs and VIC

To study the relationship between daily variations in $f o E s$ and VIC in the lower thermosphere, we used ionosonde data obtained by NICT at Kokubunji in 2009. We chose these data simply because of the relatively small number of missing data compared with other years.

Figure 2 shows the daily average foEs (blue line) and the daily average VIC (red line) in 2009 obtained at Kokubunji at four different altitudes: (a) $130 \mathrm{~km}$, (b) $120 \mathrm{~km}$, (c) $110 \mathrm{~km}$, and (d) $100 \mathrm{~km}$. The scale on the axis of the daily average VIC is adjusted so that the values are best fitted to the $f_{o} E s$ values. The results indicate that the agreement between foEs and VIC is best at $120 \mathrm{~km}$ altitude (Fig. 2b). The agreement is good not only for the seasonal variation, but also for some day-to-day variations. At altitudes of $130 \mathrm{~km}$ (Fig. 2a) and $110 \mathrm{~km}$ (Fig. 2c) there is less agreement between the two parameters, and no significant correlation is seen at $100 \mathrm{~km}$ altitude (Fig. 2d). 

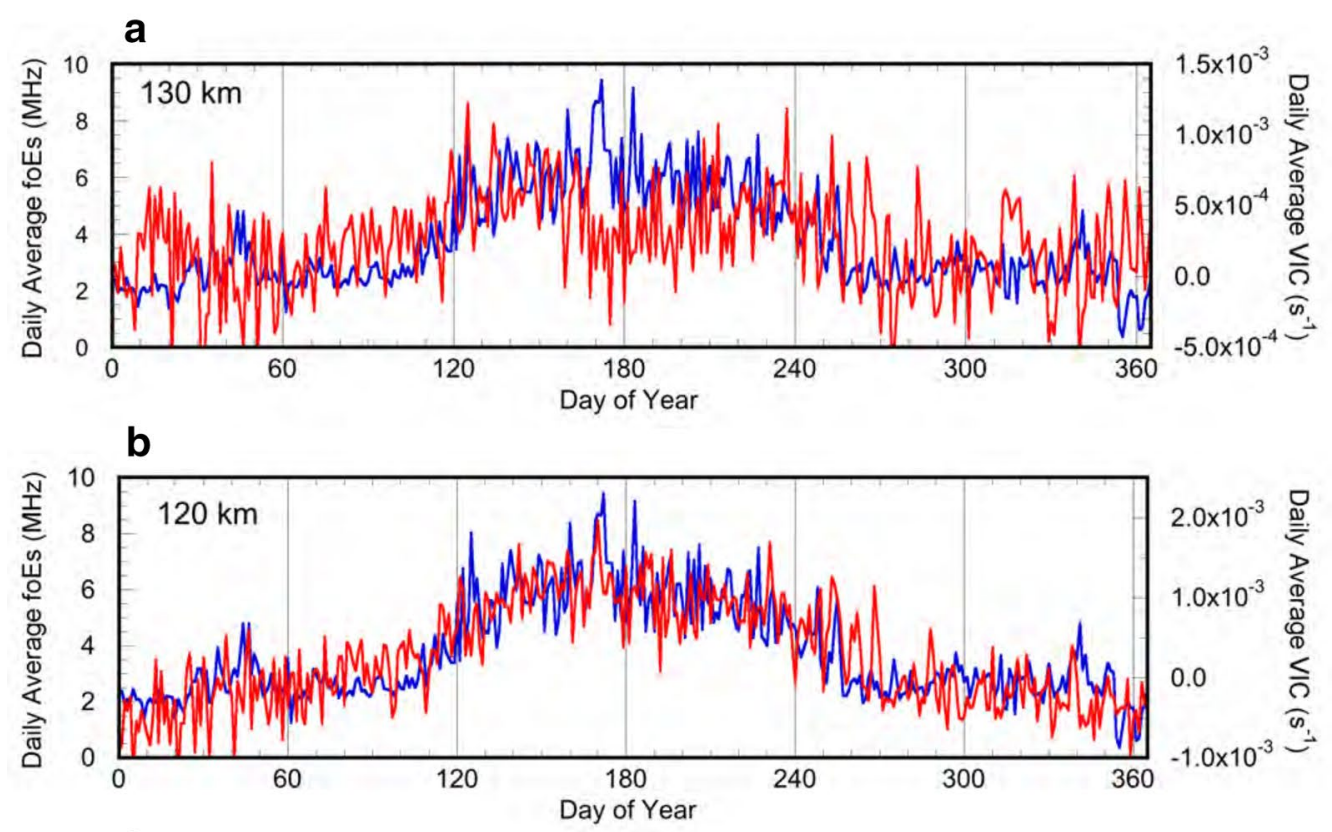

C

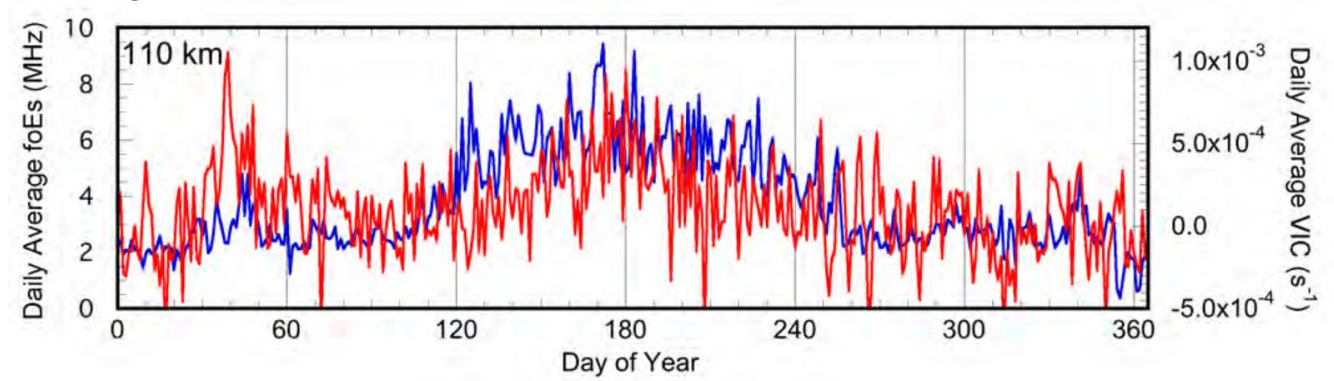

d

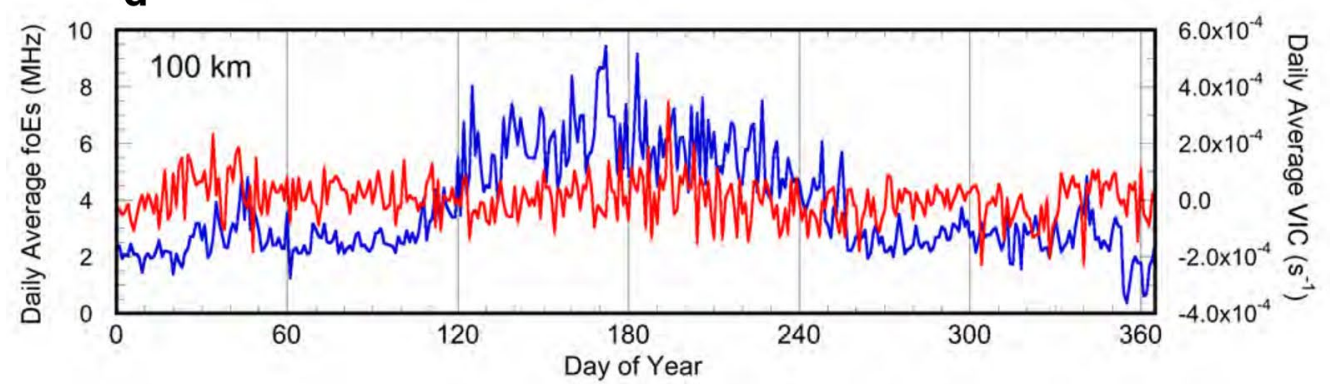

Fig. 2 Daily average foEs and daily average vertical ion convergence. Daily average foEs (blue line) and daily average vertical ion convergence (VIC) (red line) at Kokubunji in 2009 are compared at four different altitudes: a 130 km, b 120 km, c 110 km, and d $100 \mathrm{~km}$. The scales on the daily average VIC are adjusted so that the values are best fitted to the foEs values

Figure 3 shows the correlation coefficients of the daily average foEs and VIC at the four different altitudes obtained at Kokubunji in 2009. The correlation coefficient is highest at $120 \mathrm{~km}$ altitude (0.764) (Fig. 3b), while it decreases rapidly away from $120 \mathrm{~km}$ altitude: 0.347 at
$130 \mathrm{~km}$ altitude (Fig. 3a) and 0.357 at $110 \mathrm{~km}$ altitude (Fig. 3c). As mentioned before, there is negligible correlation at $100 \mathrm{~km}$ altitude (Fig. 3d).

This result implies that VIC around $120 \mathrm{~km}$ altitude plays an important role in the development of Es layers. 

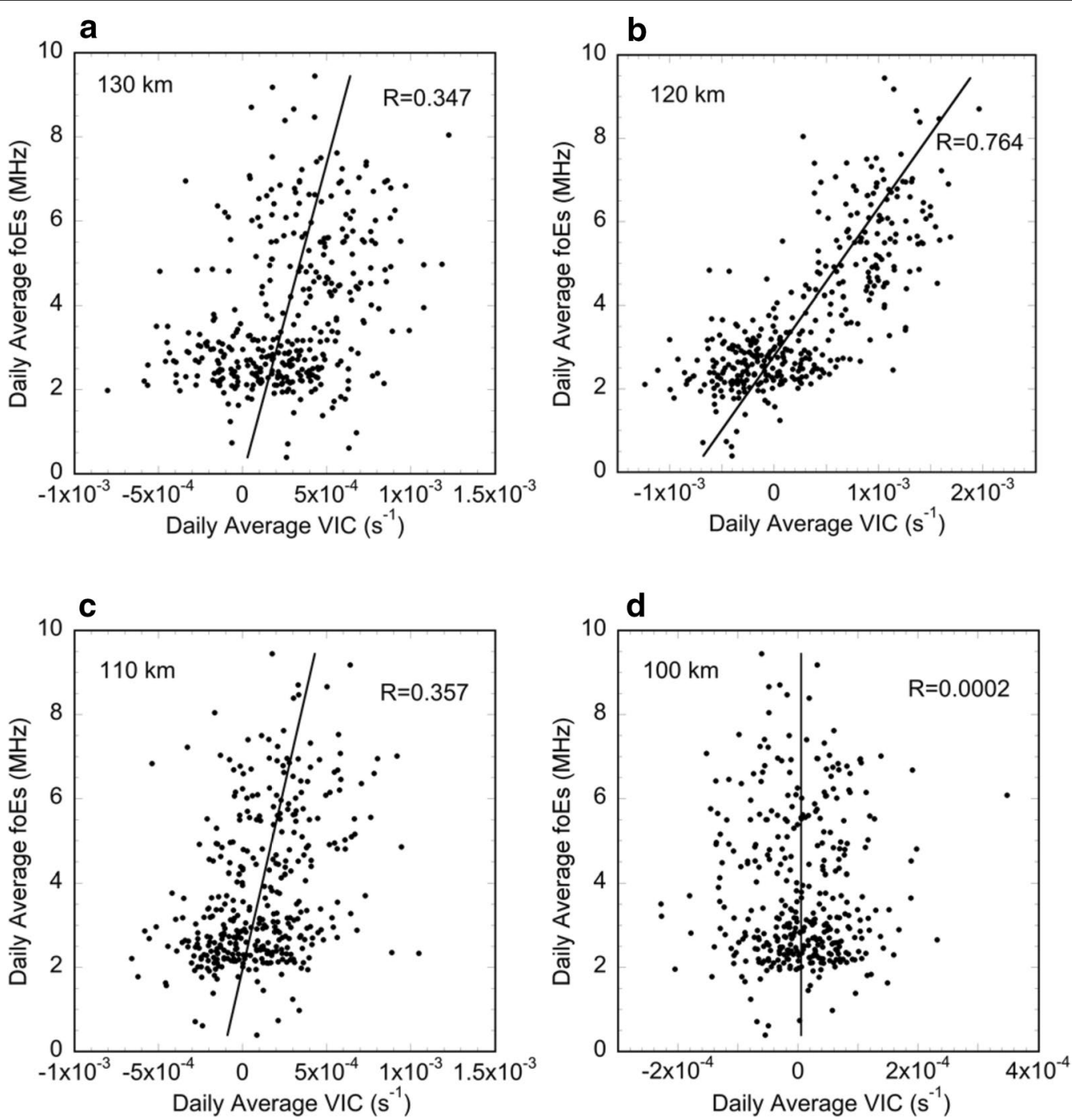

Fig. 3 Correlations of daily average foEs and VIC. Scatter plots and correlation coefficients of the daily average foEs and VIC are shown at four different altitudes at Kokubunji in 2009

However, the observation that Es layers appear most often in the region between 100 and $110 \mathrm{~km}$ altitudes (Wu et al. 2005; Arras et al. 2008). The ionosonde data used in our analysis is also consistent with the result. Figure 4 shows the altitude distribution of Es layers observed by the NICT ionosonde at Kokubunji in 2009.

A possible explanation for this inconsistency is that metallic ions accumulate in the region of about $120 \mathrm{~km}$ as a result of the ion convergence driven by a neutral wind shear, and then the metallic ion layers descend and form Es layers in the lower region of $100-110 \mathrm{~km}$ altitudes. Recently, Andoh et al. (2020) have studied the formation processes of Es layer using three-dimensional ionospheric simulation model incorporating the neutral density and velocity data produced by GAIA, which are the same as

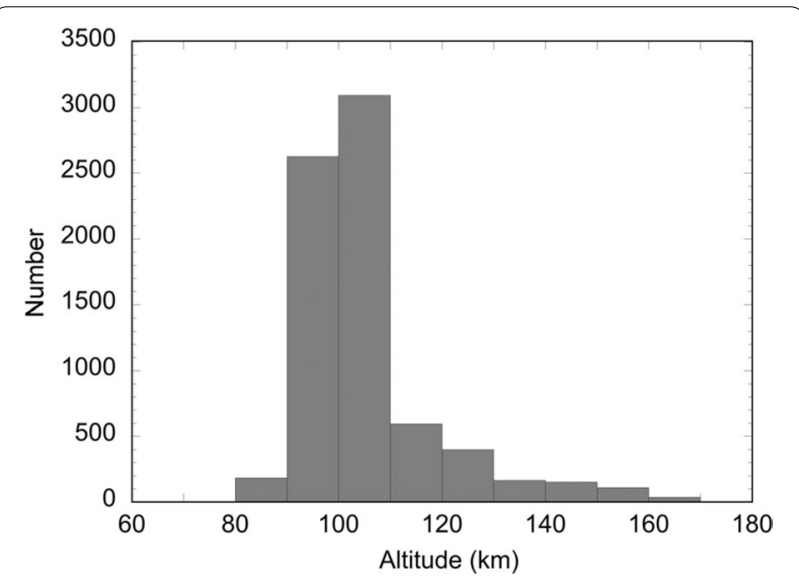

Fig. 4 Histogram of the distribution of Es layer altitude for Kokubunji in 2009. The manually scaled 1 -h data obtained by the NICT ionosonde were used. The plot indicates that Es layers appear most often in the 100-110 km altitude region. 
used in our paper. This study demonstrated that the Es layer is initially formed at around $120 \mathrm{~km}$ on the average, and that the layer descends to lower altitudes, increasing its electron density. This picture seems consistent with observational result obtained by Haldoupis et al. (2006), Prasad et al. (2012), Yuan et al. (2013), Chu et al. (2014). The Es layer tends to stay at around $100 \mathrm{~km}$ because the background bulk neutral wind is weaker. But the wind shear is even stronger at $100 \mathrm{~km}$ than at $120 \mathrm{~km}$. It is expected that the Es layer at around $100 \mathrm{~km}$ is further strengthened by local smaller-scale wind shear (Larsen et al. 2005), which cannot be reproduced by the present version of GAIA. In this paper, we focus on the possibility of Es prediction using VIC at $120 \mathrm{~km}$ altitude $\left(V I C_{120}\right)$.

In addition to the year of 2009, we also analyzed foEs data obtained at Kokubunji for the years from 2010 to 2014, which cover the period from the solar minimum to solar maximum. Although the dependence of Es layer formation on the solar cycle is insignificant compared with the seasonal dependence, some studies indicate that $f o E s$ has a weak solar cycle dependence (Maksyutin et al. 2001; Pezzopane et al. 2015, 2016), suggesting the possibility of year-to-year differences in the relationship between $f_{0 E S}$ and VIC. However, we found that the correlation between $f o E s$ and VIC does not change significantly with the year. The correlation coefficients between the daily average foEs and VIC for the years of 2009-2014 are shown in Fig. 5. Although there are small differences in the correlation coefficients among the years, the altitude dependence of the correlation coefficient is almost the same in each year: the correlation coefficient has a peak at about $120 \mathrm{~km}$ altitude and is smaller at altitudes above and below $120 \mathrm{~km}$. This result suggests that $V I C_{120}$ is a key parameter in the formation process of Es layers and that the relationship between $V I C_{120}$ and $f o E s$ does not depend significantly on the year.

\section{Comparison of daily maximum foEs and VIC}

The results described in the previous section indicate that there is a strong relationship between the daily average $f o E s$ and $V I C_{120}$. For practical space weather forecast, however, predicting the daily maximum of $f o E s$ is more important than predicting the daily average $f o E s$ because Es layers with higher electron densities have more influence on communication and broadcast systems.

Figure 6 shows comparisons between the daily maximums of foEs (blue line) and VIC (red line) in 2009 obtained at Kokubunji. The daily maximums of both $f o E s$ and VIC show greater variation than the daily average values (Fig. 2). While the daily average $f o E s$ is always less than $10 \mathrm{MHz}$ (Fig. 2), the daily maximum foEs is much larger and occasionally exceeds $20 \mathrm{MHz}$ (Fig. 6).

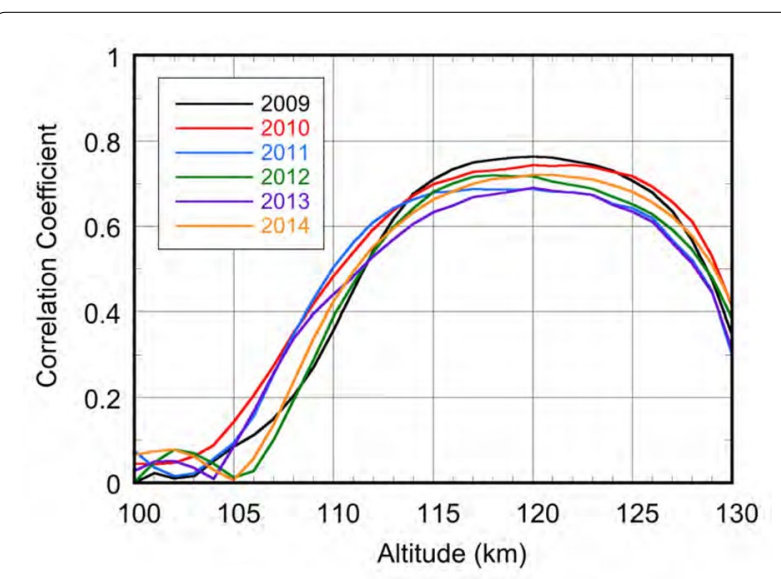

Fig. 5 Correlation coefficients of the daily average foEs and $V I C_{120}$. Correlation coefficients of the daily average $\mathrm{fo} E \mathrm{~s}$ and the vertical ion convergence at $120 \mathrm{~km}$ altitude are shown for the years of 2009-2014 at Kokubunji in 2009

The agreement between the daily maximums of foEs and $V I C_{120}$ is somewhat less than that of the daily averages (Fig. 2), although the best agreement still occurs at $120 \mathrm{~km}$ altitude. The occasional large enhancement of the daily maximum of $f o E s$ suggests the existence of a sudden increase in local neutral wind shears, which is probably associated with gravity waves with a large amplitude or shear instabilities (Nygrén et al. 1990; Larsen 2002; Larsen et al. 2005). The daily maximum of VIC also occasionally exhibits sudden enhancement, which does not always match the observed $f o E s$ enhancement. Local small-scale wind shears responsible for the large foEs cannot be reproduced by global atmosphere-ionosphere models such as GAIA. This is analogous to the fact in meteorology that the maximum instantaneous wind speed is much more difficult to predict than the average wind speed. Figure 7 shows scatter plots of the daily maximums of $f_{o} E s$ and VIC at the four different altitudes obtained at Kokubunji in 2009. The correlation coefficient is highest at $120 \mathrm{~km}(0.536)$ (Fig. 7b). This value is less than that for the daily averages (0.764) (Fig. 3b), indicating that the prediction of the daily maximum $f o E s$ is more difficult than that of the daily average foEs.

\section{Comparison of hourly variations between foEs and VIC}

Although present numerical models cannot accurately reproduce the temporal variations in $f o E s$, it is meaningful to compare the observed foEs and $V I C_{120}$. Figure 8 shows 1 -h values of $f o E s$ (blue line) and $V I C_{120}$ (red line) obtained at Kokubunji for three different periods in 2009: 13-23 June, 18-28 August, and 17-27 October. Figure $8 \mathrm{a}$ corresponds to the most active period of Es layer formation, and Fig. 8b, c are moderate 

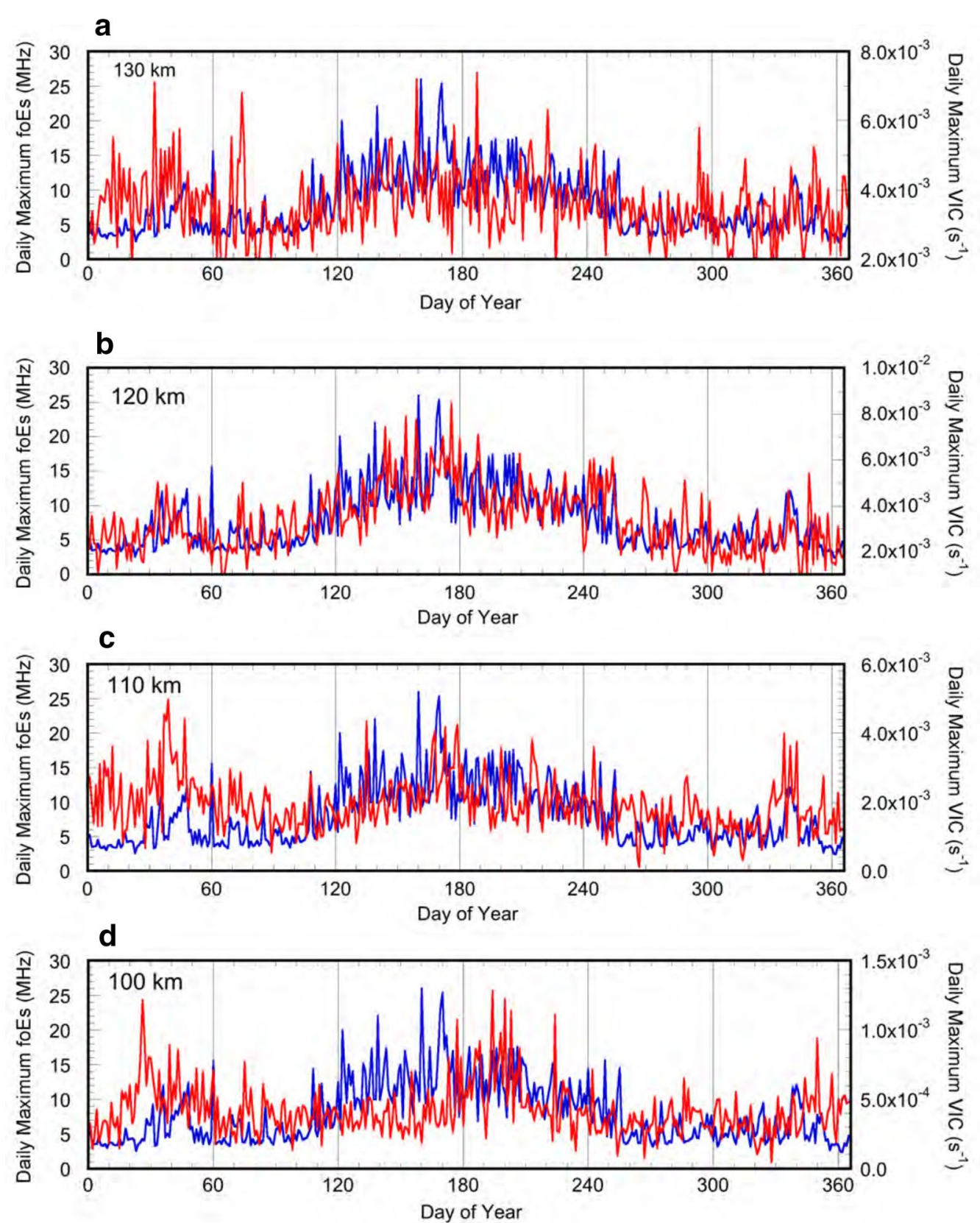

Fig. 6 Daily maximums of foEs and daily maximums of VIC. The daily maximums of foEs (blue line) and the daily maximums of the vertical ion convergence (VIC) are compared at four different altitudes (red line) in 2009 at Kokubunji

and quiet periods, respectively. The agreement between maximum $f o E s$ and maximum $V I C_{120}$ is not particularly good, but the phases of the variations are in reasonable agreement. For the less active periods (Fig. 8b, c), the overall amplitudes of both foEs and $V I C_{120}$ decrease in a similar manner.

It appears that diurnal variation is dominant for the observed $f o E s$, while semidiurnal variation is dominant for $V I C_{120}$. In addition, in some cases, peaks of the $f o E s$ and $V I C_{120}$ appear to occur simultaneously. If variations in $V I C_{120}$ are related to descending layers associated with tidal variations (Haldoupis et al. 2006; Andoh et al. 2020), peak of $f o E s$ should occur a few hours later than the peak of $V I C_{120}$. These inconsistencies indicate that the present version of GAIA does not have sufficient resolution or accuracy to reproduce the hourly variations in neutral winds in the lower thermosphere, which are likely to be associated with small-scale 

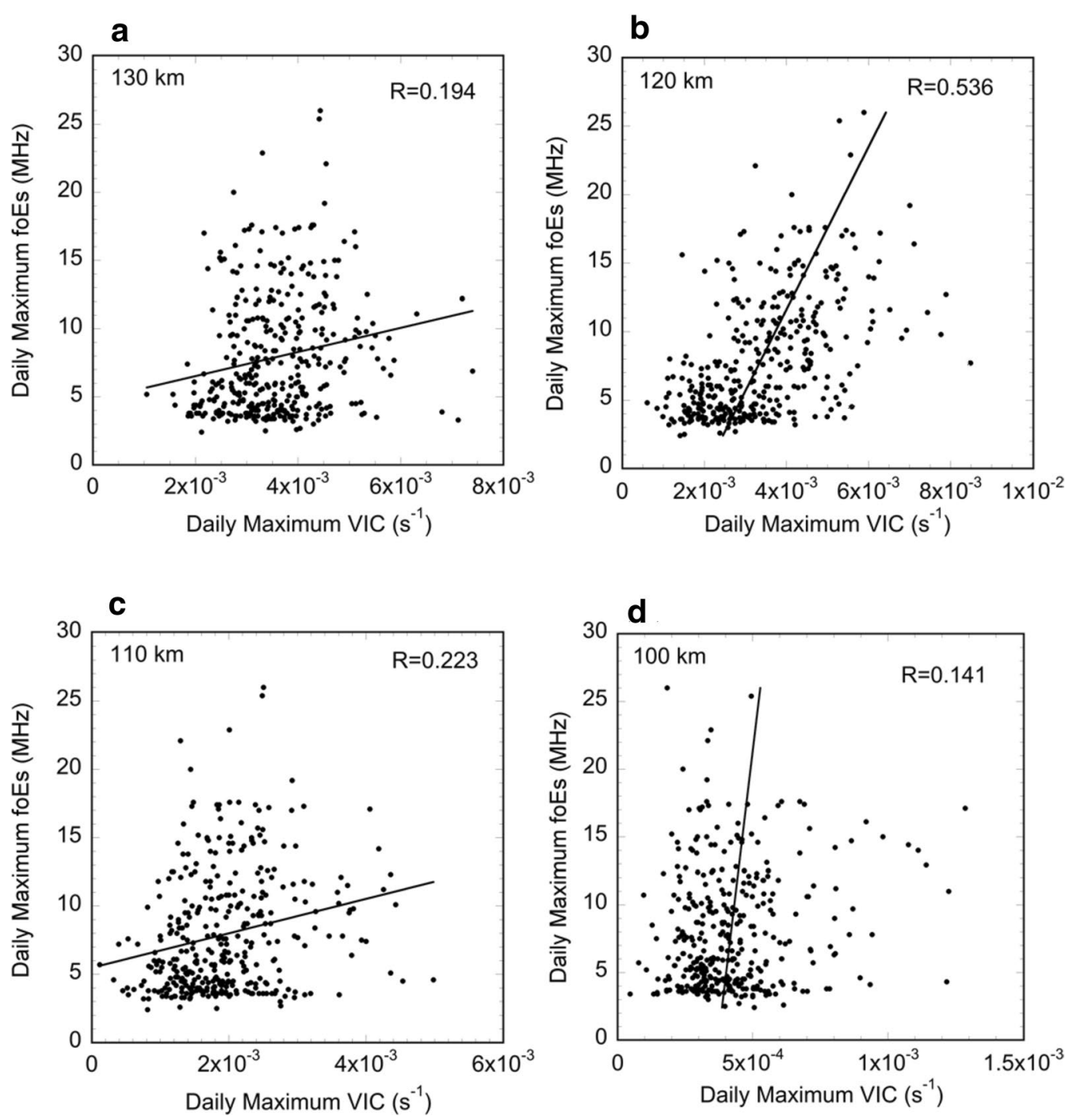

Fig. 7 Correlation coefficients of the daily maximums of foEs and VIC. Scatter plots and correlation coefficients of the daily maximums of foEs and the daily maximums of the vertical ion convergence (VIC) are shown at four different altitudes at Kokubunji 2009

gravity waves or shear instabilities around $100 \mathrm{~km}$ altitude. Although the magnitude and the time of the $f o E s$ peak cannot be predicted by GAIA, studies of Andoh et al. (2020) suggest that the basic behavior of Es layer is likely to be reproduced by GAIA.

\section{Prediction of Es layer occurrence using VIC at $120 \mathrm{~km}$}

As mentioned before, in space weather forecast it is more practical to predict daily maximum $f o E s$ than the daily average $f_{o E s}$. In the previous section, we compared the daily maximums of $f o E s$ and $V I C_{120}$. We found that the correlation between the daily averages of $f o E s$ and $V I C_{120}$ was stronger than the correlation between the daily maximums of $f_{o E s}$ and $V I C_{120}$. This is probably because the daily maximum values of both $f o E s$ and $V I C_{120}$ tend to fluctuate more than the daily average values, which results in lower correlation with the observed foEs.

Figure 9a shows the daily maximum foEs (blue line) and the daily average $V I C_{120}$ (red line) obtained at Kokubunji in 2009. For this case the correlation coefficient is 0.679 , which is somewhat higher than the correlation coefficient $(0.536)$ of the daily maximums of foEs and $V I C_{120}$ (Fig. 9b). Thus, the daily average $V I C_{120}$ is a better index for predicting the daily maximums of foEs. Using the relationship between the maximum foEs and the average $V I C_{120}$, we present an experimental method to deduce the daily maximum of $f_{0} E s$ from the daily average $V I C_{120}$. 

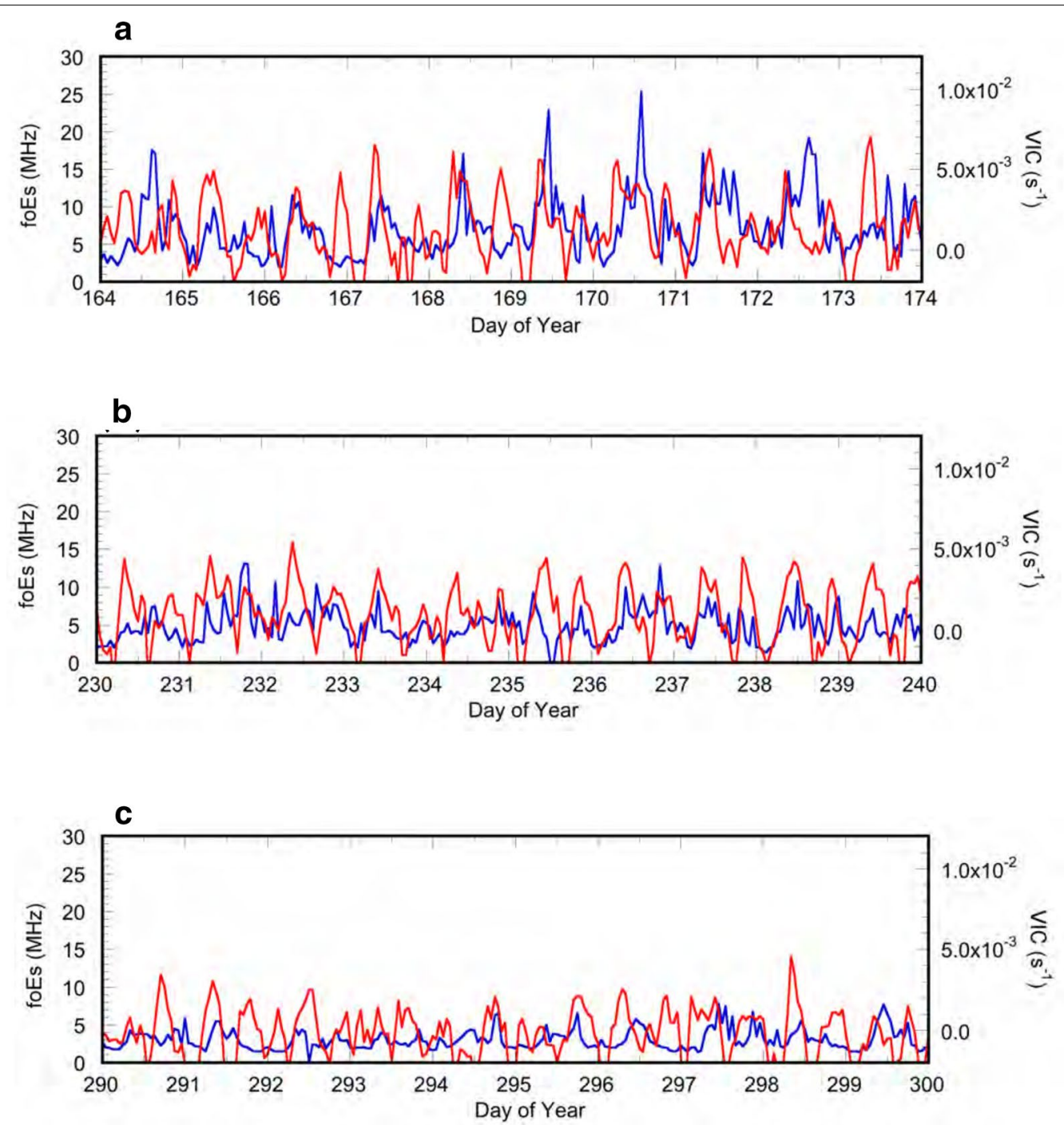

Fig. 8 One-hour values of foEs and $V I C_{120}$. One-hour values of foEs (blue line) and the vertical ion convergence at $120 \mathrm{~km}$ altitude (VIC $\left.C_{120}\right)$ (red line) are plotted for three different periods at Kokubunji in 2009. a corresponds to the most active period, and $\mathbf{b}$, $\mathbf{c}$ are moderate and quiet periods, respectively

Strictly speaking, this is not a prediction because the calculated $V I C_{120}$ is a present value, not a future value, since the present JRA-55 data is incorporated in the model, but in this paper we call it a prediction for convenience. In any prediction, if no information is available, the only way of predicting tomorrow's condition is to assume that tomorrow will be the same as today, which is called "persistence prediction". For a prediction method to be useful, its accuracy must be higher than that of the persistence prediction. Therefore, we examined the prediction scheme with daily average $V I C_{120}\left(V I C_{120, \mathrm{~d} \text {-ave }}\right)$ and compared the accuracy with that of the persistence prediction. As mentioned before, the criterion for Es layer occurrence is defined as $f o E s \geq 8 \mathrm{MHz}$. One of the prediction schemes using $V I C_{120, \text { d-ave }}$ is to use criteria with threshold values, in which the occurrence and the absence of the Es layer are determined on the basis of the following criteria:

If $V I C_{120, \text { d-ave }} \geq 6.1 \times 10^{-4}$, the Es layer is present, If $V I C_{120, \mathrm{~d} \text {-ave }} \leq-2.0 \times 10^{-4}$, the Es layer is absent, If $6.1 \times 10^{-4}>V I C_{120, \mathrm{~d} \text {-ave }}>-2.0 \times 10^{-4}$, the persistence prediction applies.

The threshold values in the above criteria were determined to maximize the prediction accuracy, and they 
Table 1 Contingency table for the categorical forecast of Es layer occurrence

\begin{tabular}{|c|c|c|c|c|c|c|c|}
\hline \multirow{2}{*}{\multicolumn{2}{|c|}{ (a) }} & \multicolumn{2}{|c|}{ Occurrence } & \multirow{2}{*}{\multicolumn{2}{|c|}{ (b) }} & \multicolumn{2}{|c|}{ Occurrence } \\
\hline & & Yes & No & & & Yes & No \\
\hline \multirow{2}{*}{ 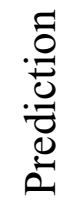 } & Yes & 112 & 32 & \multirow{2}{*}{ 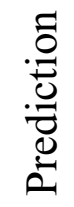 } & Yes & 124 & 31 \\
\hline & No & 32 & 189 & & No & 20 & 190 \\
\hline \multicolumn{4}{|c|}{$\begin{array}{l}\text { Accuracy }=0.825 \\
\text { Skill Score }=0.633\end{array}$} & \multicolumn{4}{|c|}{$\begin{array}{c}\text { Accuracy }=0.860 \\
\text { Skill Score }=0.711\end{array}$} \\
\hline
\end{tabular}

Results of (a) persistence prediction, and (b) prediction with $V / C_{120}$ are compared for the ionosonde data at Kokubunji in 2009

might vary with the year or location. Table 1 is the contingency table for the categorical forecast of Es layer occurrence for the ionosonde data obtained at Kokubunji in 2009. "Yes" indicates the occurrence of an Es layer (maximum $f o E s \geq 8 \mathrm{MHz}$ ), and "No" indicates the absence of an Es layer (maximum $f o E s<8 \mathrm{MHz}$ ). The numbers in Table 1 are the numbers of days in 2009 for the four categories. The accuracies and the skill scores for the Kokubunji 2009 data obtained by the above prediction method are also included in the table. In this analysis the Heidke skill score described by Hyvärinen (2014) is adopted. In this score, negative values indicate that the random forecast is even better; 0 indicates that the scheme has no skill (same as random forecast); 1 indicates a perfect forecast skill.

The accuracy and the skill score of the persistence prediction are 0.825 and 0.633 , respectively (Table $1 \mathrm{a}$ ). Since foEs has significant seasonal dependence, even the persistence prediction gives fairly high scores. For the prediction method using $V I C_{120, \mathrm{~d} \text {-ave }}$ (Table $1 \mathrm{~b}$ ), the accuracy and the skill score are 0.860 and 0.711 , respectively. This result suggests that using $V I C_{120,} \mathrm{~d}$-ave results in better accuracy and skill score of prediction, although the improvement is relatively small.

The small difference between the persistence prediction and the prediction of $V I C_{120, d \text {-ave }}$ comes from the fact that even the persistence prediction is able to give a high accuracy or a skill score because in summer Es layer (foEs $>8 \mathrm{MHz}$ ) occurs almost every day, while it rarely occurs in winter. The prediction of $V I C_{120}$, d-ave gives a significantly better prediction of Es occurrence only in spring and fall (mostly in late March-April and September-early October).
The method shown here is only one of ways of predicting Es layer occurrence, and there might be a better method of prediction. We will investigate various schemes to improve the accuracy of prediction (Table 2).

\section{Experimental prediction of foEs using real-time GAIA}

In actual space weather forecast, it is necessary to predict a future state of the upper atmosphere. We have recently developed a real-time and forecasting version of GAIA (GAIA-RF), which started to run in June 2019 (Tao et al. 2020). In the present GAIA-RF, meteorological reanalysis data (JRA-55) are incorporated in the lower atmosphere until about one day before the present, but magnetospheric inputs are not included. Since the effect of the magnetospheric activities on Es layer formation is thought to be insignificant (Whitehead 1989), it is adequate to use the data obtained by GAIA-RF for Es layer prediction.

After about one day before the present, the model is run without JRA-55 and produces 4-day prediction data once a day. We found that even without JRA data, the model could produce almost the same data for about 3 or 4 days ahead. Figure 10 shows comparisons of the eastward neutral wind velocity at $120 \mathrm{~km}$ for five different periods, obtained at Okinawa, starting from the same initial values at $0 \mathrm{UT}$ on the first day of 5 months in 2019: (a) July, (b) August, (c) September, (d) October, and (e) November. The black line and the red line indicate neutral wind velocities obtained with and without JRA55 data, respectively. Correlation coefficients for each day are calculated and shown in Fig. 10. In most cases, the difference between the two is very small at least for about 3 days ahead. After 4 days, the correlation coefficient decreases significantly. The results suggest that even 
Table 2 Contingency table for the 24-48 $\mathrm{h}$ categorical forecast of Es layer occurrence

\begin{tabular}{|c|c|c|c|c|c|c|c|}
\hline \multirow{2}{*}{\multicolumn{2}{|c|}{ (a) }} & \multicolumn{2}{|c|}{ Occurrence } & \multirow{2}{*}{\multicolumn{2}{|c|}{ (b) }} & \multicolumn{2}{|c|}{ Occurrence } \\
\hline & & Yes & No & & & Yes & No \\
\hline \multirow{2}{*}{ 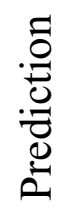 } & Yes & 52 & 21 & \multirow{2}{*}{ 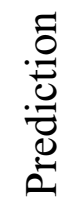 } & Yes & 53 & 18 \\
\hline & No & 20 & 28 & & No & 19 & 31 \\
\hline \multicolumn{4}{|c|}{$\begin{array}{c}\text { Accuracy }=0.661 \\
\text { Skill Score }=0.295\end{array}$} & \multicolumn{4}{|c|}{$\begin{array}{c}\text { Accuracy }=0.694 \\
\text { Skill Score }=0.368\end{array}$} \\
\hline
\end{tabular}

Results of (a) persistence prediction and (b) prediction with VIC 120 are compared for the ionosonde data for the day of year from DOY 179 to DOY 299 at Okinawa in 2019

without JRA-55 data GAIA is able to produce almost the same neutral winds as those with JRA-55 for about 3 days ahead.

Figure 11 shows comparisons of $V I C_{120}$ obtained with JRA-55 data (black line) and without JRA-55 data (red line) for the same periods as in Fig. 10, starting from the same initial conditions. Correlation coefficients for each day are also shown in Fig. 11. It is clear that the difference between $V I C_{120}$ with and without JRA-55 data is insignificant for two ahead. Beyond 3 days ahead, the correlation between the two values becomes worse, but the daily maximum values of $V I C_{120}$ still seem to be relatively small, indicating that as long as the $f o E s$ derived from $V I C_{120}$ agrees with the observed $f o E s$ of the present day, it is possible to make a forecast for foEs for 1 or 2 days ahead.

There are several possible ways to derive foEs from $V I C_{120}$. At the moment, we convert $V I C_{120}$ to predicted foEs by using the following simple linear formula:

$$
f o E s=1.25 \times 10^{3} \overline{V I C}+4.75[\mathrm{MHz}],
$$

where $\overline{V I C}\left[\mathrm{~s}^{-1}\right]$ is a 2-h average of $V I C_{120}$.

The formula to convert from $V I C_{120}$ to $f o E s$ is determined by eye so that the predicted values agree best with the observed $f_{o} E s$. This is a tentative fitting formula, and there is likely to be a better formula or method for predicting foEs. To compare the observed and predicted $f o E s$, we adopted manually scaled $f o E s$ data obtained at Okinawa in 2019 instead of at Kokubunji in 2019 because manually scaled $f o E s$ data obtained at Kokubunji from late 2019 were not available at the time of this analysis.

Figure 12 shows comparisons between the predicted $f o E s$ and the observed $f o E$ s for three different periods obtained at Okinawa in late 2019. Figure 12a schematically illustrates the relationship between the prediction time and the predicted period of $f o E s$. It is assumed that the prediction is made at 0 JST on Day $N$ for the period of 24-48 h later (Day $N+1$ ). Figure $12 \mathrm{~b}-\mathrm{d}$ shows the hourly values of predicted $f o E s$ for which each day corresponds to the "predicted period" of Fig. 12a. The red line indicates a series of predicted $f_{0 E S}$ for $24-48 \mathrm{~h}$, and the black line indicates the observed foEs obtained by the ionosonde at Okinawa.

Although the daily variations in the predicted foEs are similar to the observed $f o E s$, the agreement is not very good. In particular, a large enhancement of $f o E s$ over $15 \mathrm{MHz}$ occasionally observed in summer could not be reproduced. It appears that the present version of GAIA is not able to reproduce a magnitude of $f o E s$ especially large enhancements of $f o E s$. In fact, the correlation between the observed $f_{0 E s}$ and the predicted $f o E s$ is rather small ( 0.213) (Fig. 13). However, it is still possible to predict Es occurrence $(f o E s>8 \mathrm{MHz})$ if we choose an adequate scheme.

The following is the scheme, in which the occurrence and the absence of the Es layer for "the day after tomorrow" are determined using the predicted $f_{o} E s$ and the daily maximum of $f o E s$ for today $\left(f o E s_{\text {dmax }}\right)$.

If $f o E s_{\operatorname{dmax}} \geq 15 \mathrm{MHz}$, the Es layer will occur regardless of VIC prediction,

If $15 \mathrm{MHz}>f o E s_{\mathrm{dmax}}>6.2 \mathrm{MHz}$, the VIC-predicted foEs applies,

If $f o E s_{\mathrm{dmax}}<6.2 \mathrm{MHz}$, the Es layer will be absent regardless of VIC prediction. 

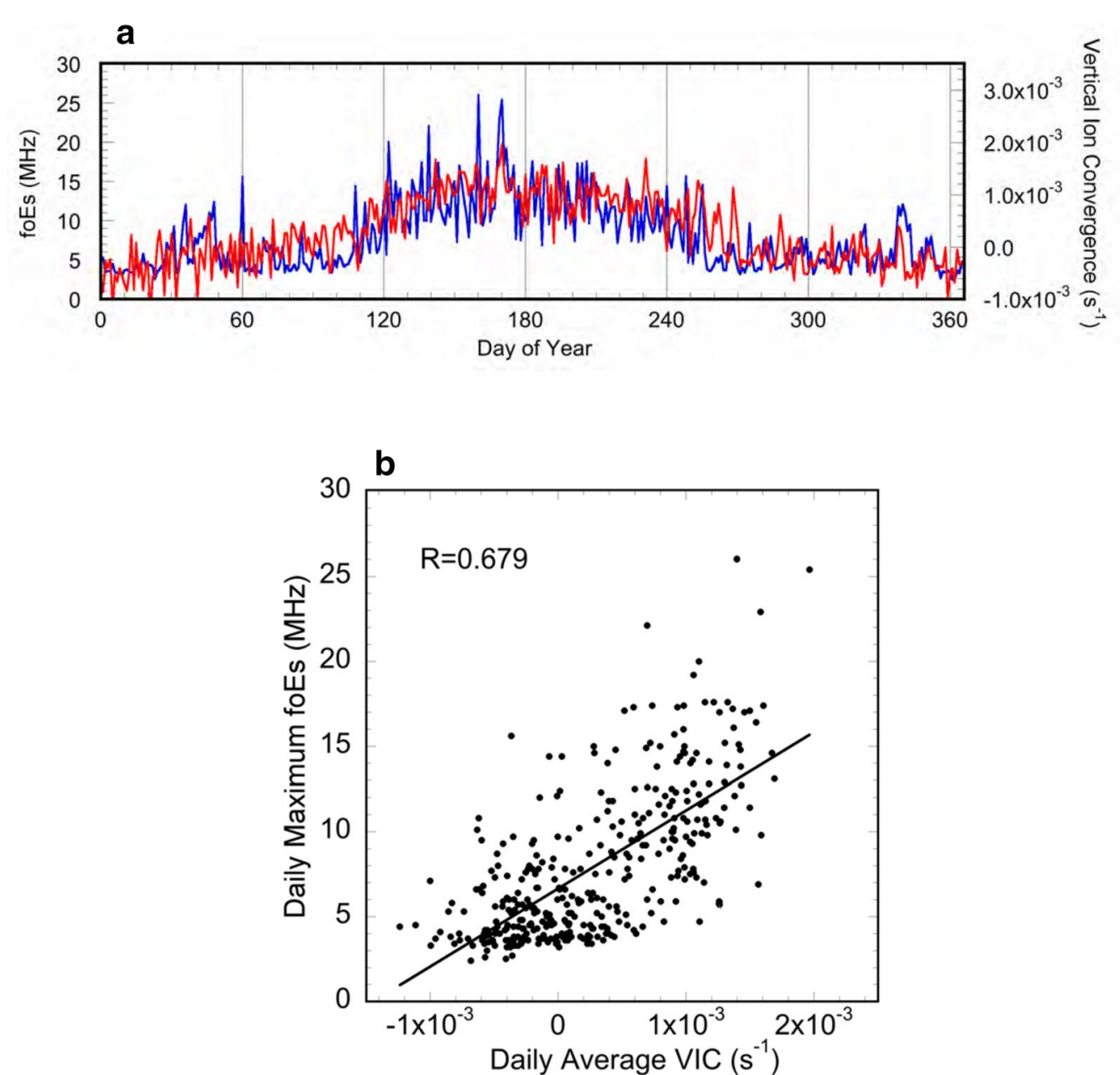

Fig. 9 Daily maximum foEs and daily average $V I C_{120}$. a Daily maximum foEs (blue line) and the daily average vertical ion convergence at $120 \mathrm{~km}$ altitude $\left(V / C_{120}\right)$ (red line) at Kokubunji 2009. b Scatter plot and correlation coefficient of the data in a

This is based on the idea that when the Es is very active or inactive today, it is better to trust the persistence prediction rather than the prediction with VIC.

Both the persistence prediction and the prediction using VIC have less accuracies and skill scores partly because the prediction is for the day after tomorrow and partly because $f_{o} E s$ in late 2019 at Okinawa shows more complicated variations than $f_{o} E s$ in 2009 at Kokubunji shown in Table 1. It is found that the prediction using VIC slightly improves the accuracy and score.

Further analysis of the observed and predicted $f_{0} E s$ for a much longer period is necessary to evaluate the prediction accuracy and to develop a better prediction scheme. We plan to construct a system for Es layer forecast that displays the predicted foEs and the observed $f o E s$ in real time.

\section{Discussion and conclusions}

The development of a system for numerically predicting space weather disturbances is an important issue. To simulate ionospheric disturbances, a number of global ionosphereatmosphere models have been constructed (e.g., Codrescu et al. 2012; Qian et al. 2014; Liu et al. 2018), which are successful in reproducing large-scale structures and variations of the ionosphere. The formation processes of Es layers have also been studied using various types of numerical models (MacLeod 1966; Kato et al. 1972; Mathews and Bekeny 1979; Earle et al. 1998; Arras et al. 2008; Christakis et al. 2009; Chu et al. 2011, 2014; Yeh et al. 2014; Chu and Yu 2017). However, it is still difficult to numerically reproduce the structures and variations of the observed $f o E s$ of Es layers.

In our study, instead of reproducing the structure of Es layers, we searched for ionospheric parameters that have strong correlations with the observed foEs. Although the agreement between $V I C_{120}$ and $f o E s$ is not very good in 

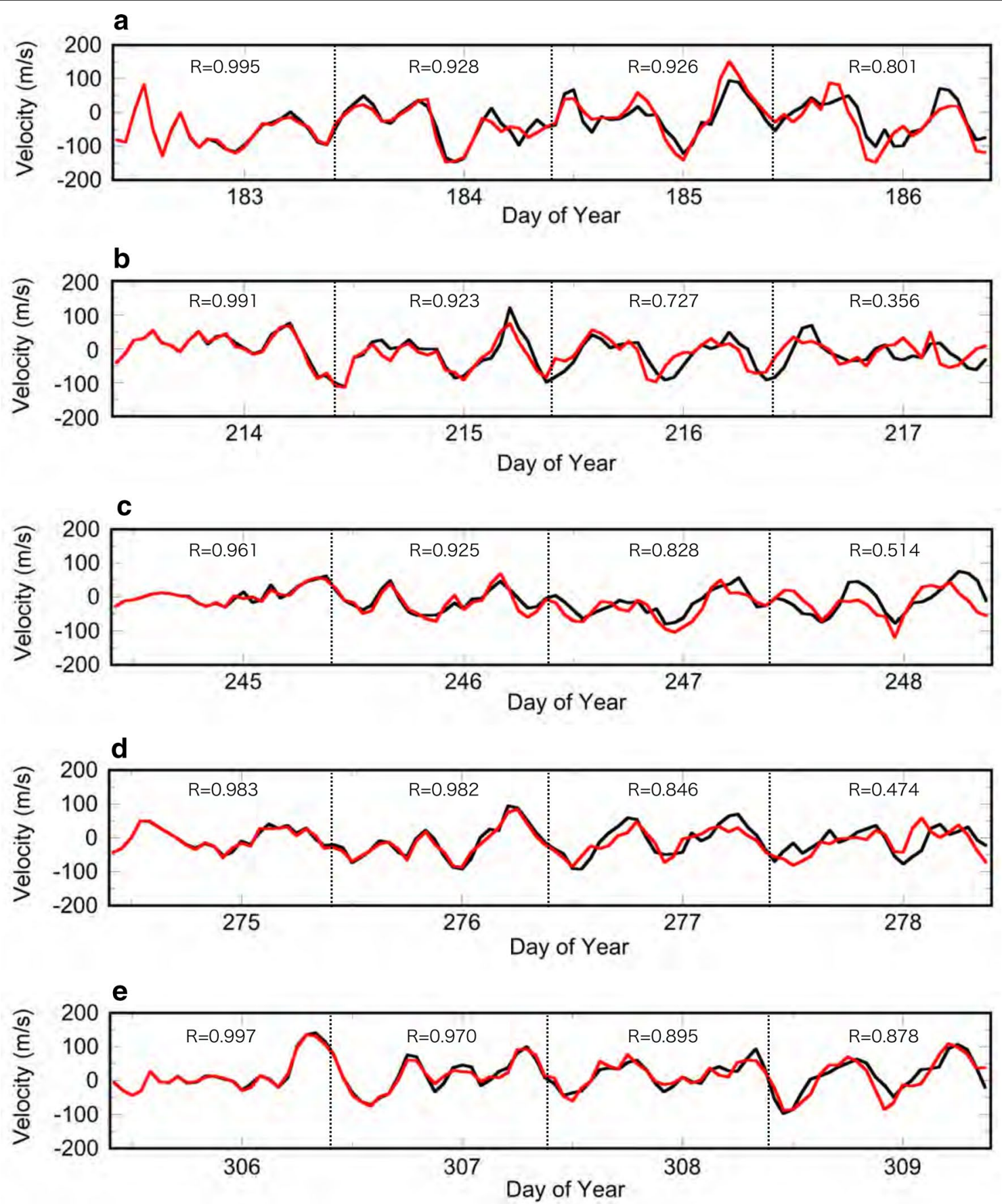

Fig. 10 Comparisons of neutral wind velocities with and without JRA-55. The eastward neutral wind velocities at $120 \mathrm{~km}$ with and without JRA-55 for five different periods in Okinawa 2019 are compared, starting from the same initial values at 0 UT of the first day of the 5 months in 2019: a July, b August, c September, d October, and e November. The black line and the red line indicate neutral wind velocities with and without JRA-55, respectively

the present version of GAIA, the results suggest a possibility that $V I C_{120}$ can be used as an index to predict the daily occurrence of Es layers. The fact that $V I C_{120}$ is in better agreement with $f o E s$ than $V I C$ at other altitudes also suggests that the accumulation of metallic ions around $120 \mathrm{~km}$ altitude plays an important role in Es layer formation. 


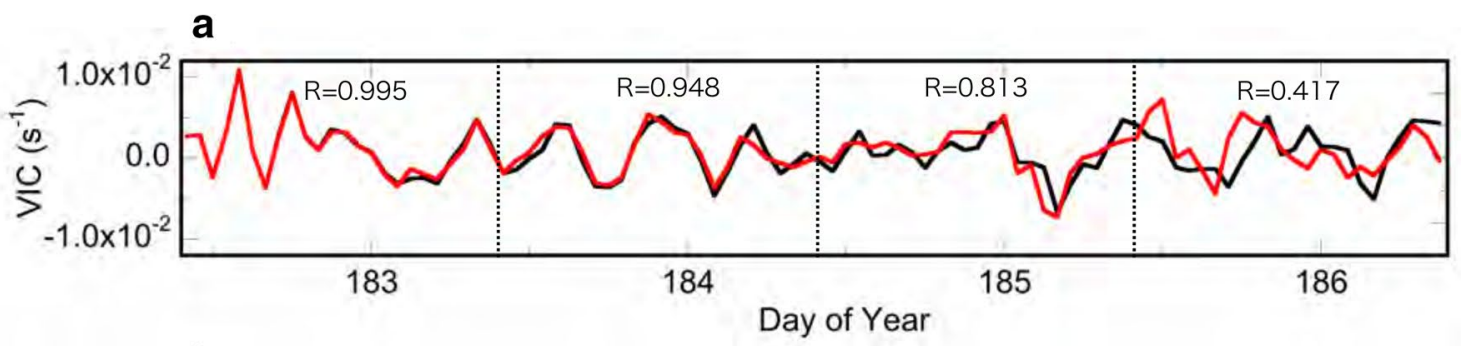

b

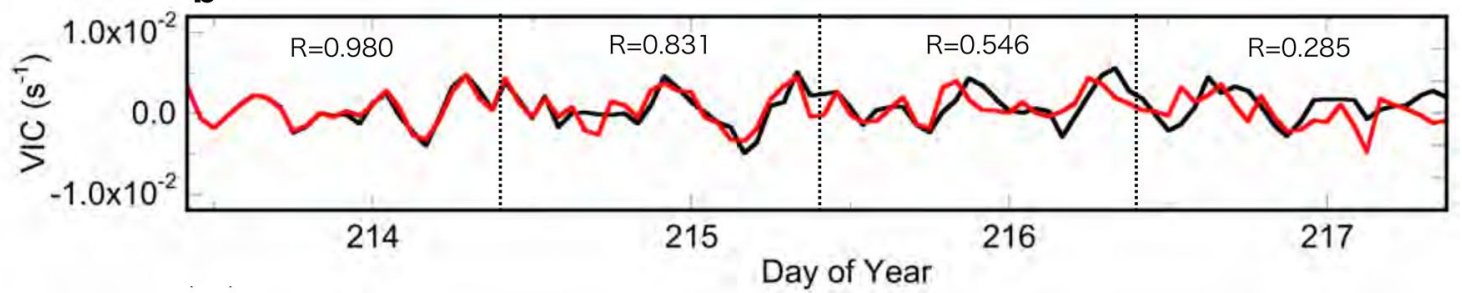

c
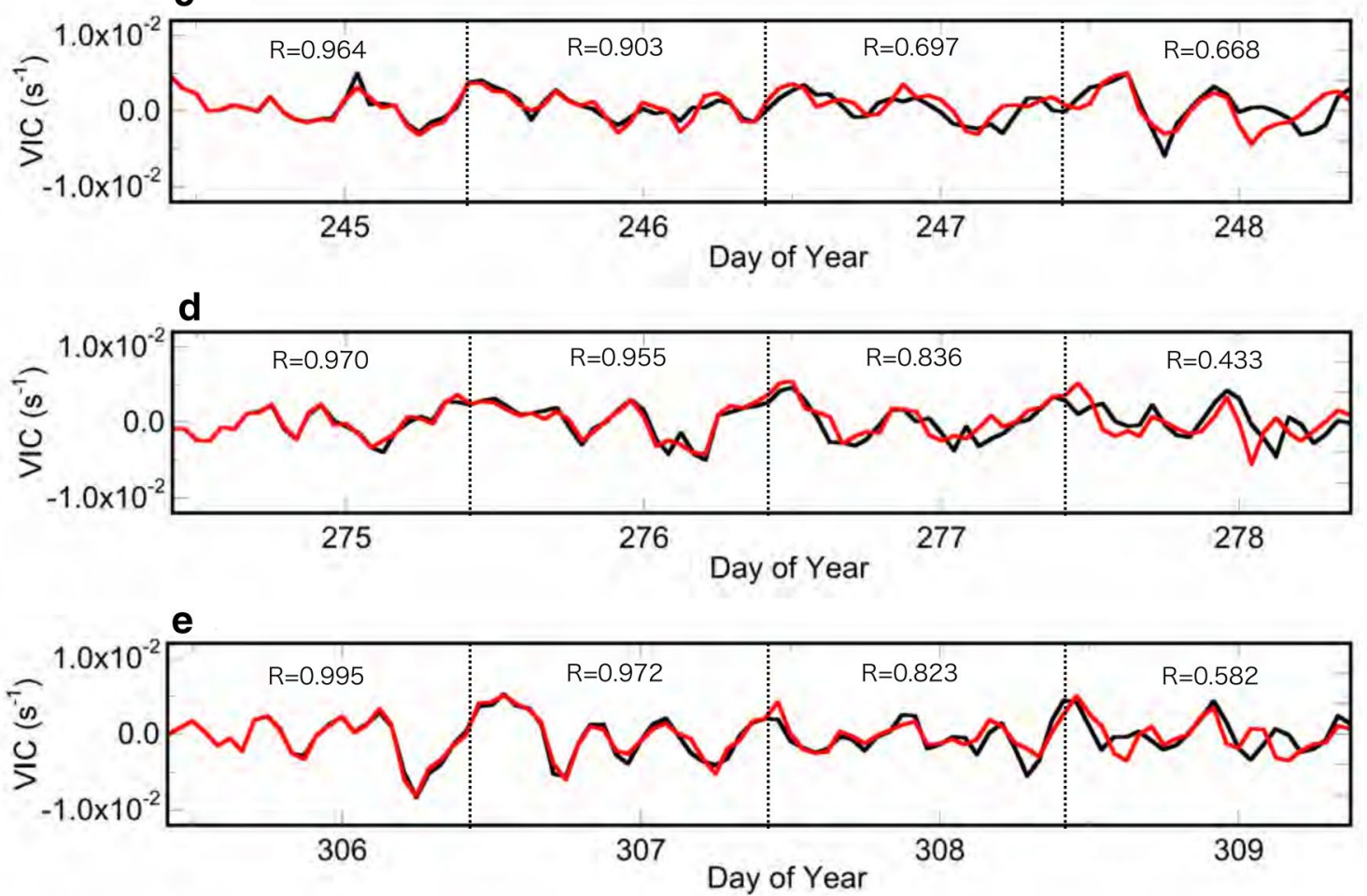

Fig. 11 Comparisons of VIC 120 with and without JRA-55. The vertical ion convergence values at $120 \mathrm{~km}\left(V I C_{120}\right)$ with and without JRA-55 are compared for the same periods as Fig. 10, starting from the same initial values. The black line and the red line indicate VIC with and without JRA-55, respectively. Numbers for each day are correlation coefficients of VIC 120 with and without JRA-55

Es layer prediction requires the prediction of thermospheric winds, which must be accomplished without using the meteorological reanalysis data in GAIA. To test the predictivity of neutral winds in the lower thermosphere, we compared two simulations: one with JRA-55 data and one without JRA-55 data. The simulated eastward neutral winds at $120 \mathrm{~km}$ in Fig. 10 demonstrate that even without meteorological reanalysis data, almost the same neutral wind in the lower thermosphere can be produced as that with JRA- 55 data for about 3 or 4 days 

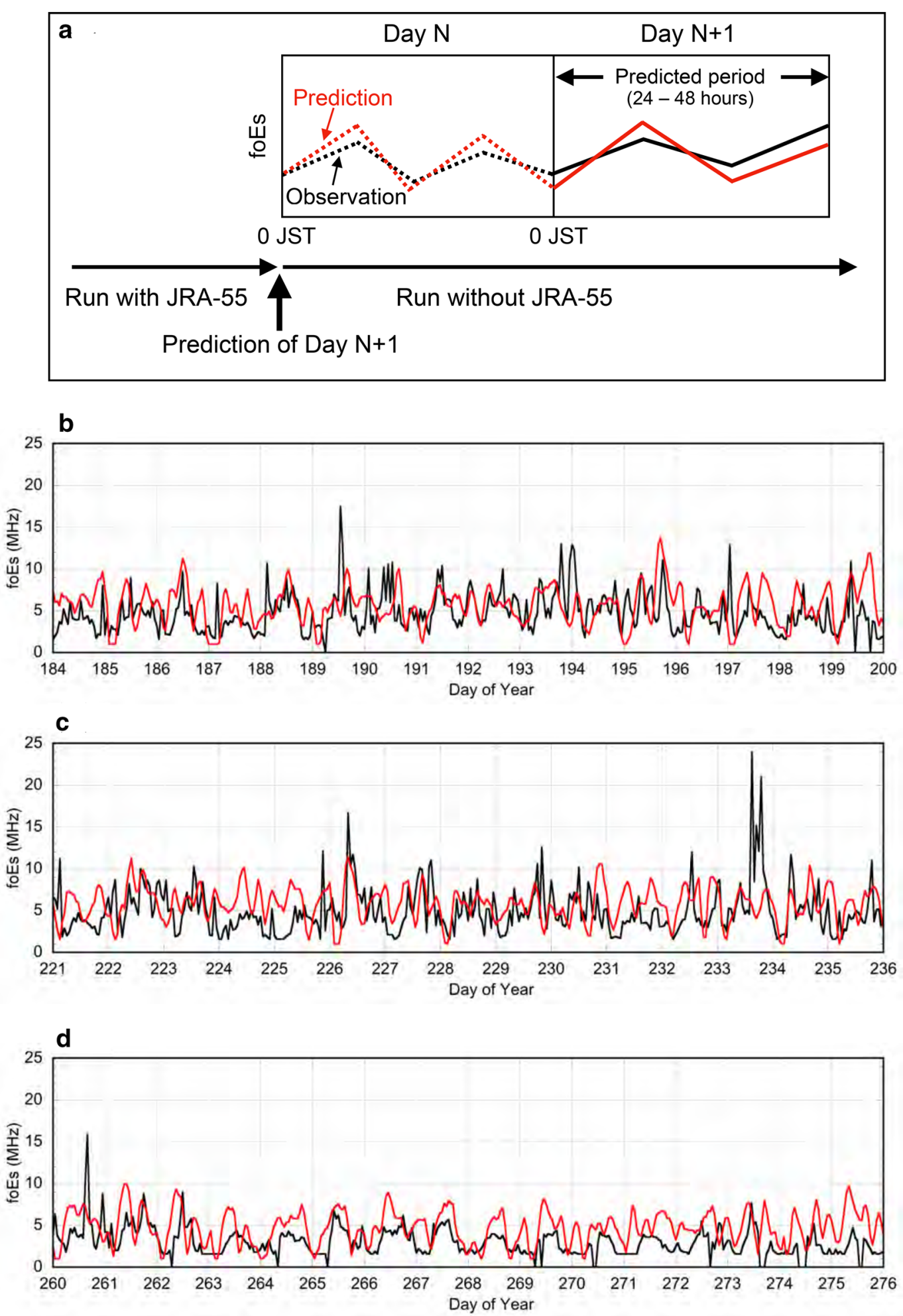

Fig. 12 Comparisons between predicted foEs and observed foEs. a Schematic figure showing the prediction time and the predicted period. Prediction for the 24-48 $\mathrm{h}$ later is made at 0 JST. The predicted foEs and the observed foEs for three different periods at Okinawa in late 2019 are compared: b DOY 184-200, c DOY 221-236, and d DOY 260-276. The red line indicates a series of predicted foEs of 24-48 h after the start of "free run" (without JRA-55 data). The black line indicates the observed foEs obtained by the ionosonde at Okinawa 


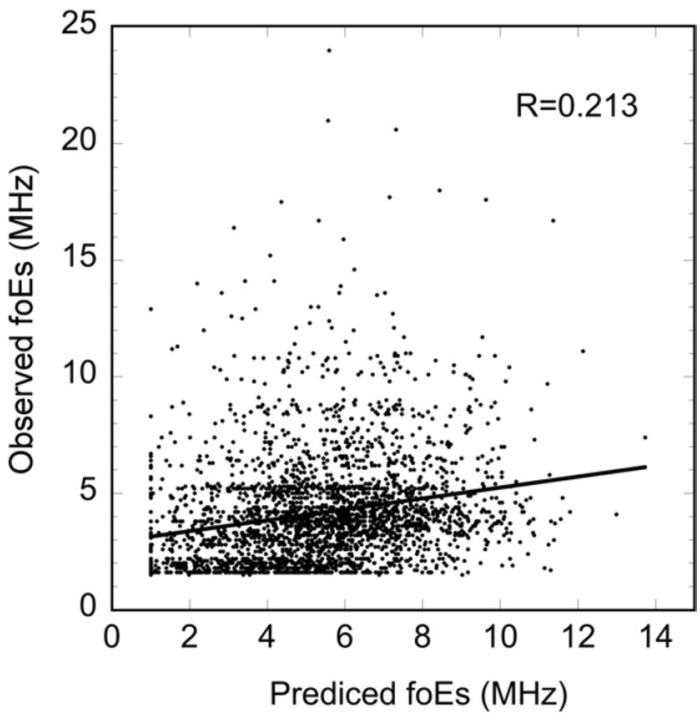

Fig. 13 Correlation coefficients of the observed foEs and predicted foEs. Scatter plots and correlation coefficients of 1-h data of the observed foEs and the predicted foEs are shown using the data from DOY 179 to DOY 299 at Okinawa in 2019

ahead, indicating that GAIA is able to reproduce meteorological processes in the lower atmosphere fairly realistically. To further improve the accuracy of neutral wind prediction in the thermosphere, it is possible to incorporate weather forecast data of the lower atmosphere into GAIA. This method may enable us to make 1-week forecasts of Es layer occurrence.

We adopted $V I C_{120}$ obtained by GAIA as an index for foEs prediction, but other parameters or their combination might give a better result than those in the present study. Since our present analysis is only for the period of July-December 2019, further analysis of data of extended periods is necessary to obtain more suitable parameters that improve the prediction accuracy.

As mentioned before, it is possible to simulate Es layers by including metallic ion species in GAIA. We are currently developing a simulation model that self-consistently reproduces an Es layer in the neutral wind in GAIA. This approach, however, has some uncertainties in the initial distribution of metallic ions, which originate from meteor influx into the upper atmosphere. Since the rate of meteor influx has been roughly estimated (Singer et al. 2004; Campbell-Brown and Jones 2006; Fentzke and Janches 2008), empirical models of the meteor influx rate can be used in upper atmosphere models (Feng et al. 2013).

There is also a significant uncertainty in the thermospheric wind in numerical models, which is critical to modeling Es layer formation. Unfortunately, there are not enough observations of the neutral wind in the lower thermosphere, and it is practically impossible to validate the modeled neutral winds in the lower thermosphere. We incorporate the JRA-55 meteorological reanalysis data in GAIA in the lower atmosphere below about $30 \mathrm{~km}$ altitude, but there are some limitations to the accuracy of the lower-atmospheric parameters. Despite some uncertainties with the parameters in models, numerical modeling of the Es layer is a promising approach to the practical prediction of Es layer occurrence.

At the Space Weather Forecast Center of NICT, a realtime forecasting system for the ionosphere has recently been developed. The system can predict atmosphereionosphere conditions for 3 or 4 days ahead. Using the forecast data obtained by the system, we have developed a tentative prediction scheme and given preliminary results for the prediction of Es layer occurrence. The results indicate that VIC or other ionospheric parameters derived from a numerical model can be used as a practical index for the prediction of Es layer occurrence.

\section{Abbreviations}

DOY: Day of year; Es: Sporadic E; GAIA: Ground-to-topside model of Atmosphere and lonosphere for Aeronomy; GAIA-RF: Real-time and forecast version of GAIA; HF: High-frequency; IGRF: International Geomagnetic Reference Field; JRA-55: Japanese 55-year reanalysis; JST: Japan Standard Time; NCEl: National Centers for Environmental Information; NICT: National Institute of Information and Communications Technology; NOAA: National Oceanic and Atmospheric Administration; UT: Universal time; VHF: Very high-frequency; VIC: Vertical ion convergence; $\mathrm{VIC}_{120}$ : Vertical ion convergence at $120 \mathrm{~km}$ altitude; $\mathrm{VIC}_{120, \text { d-ave: }}$ Daily average of vertical ion convergence at $120 \mathrm{~km}$ altitude.

\section{Acknowledgements}

This work was carried out with support from the Project for Solar-Terrestrial Environment Prediction (PSTEP) in Grant-in-Aid for Scientific Research on Innovative Areas from MEXT/Japan. The meteorological reanalysis data are obtained from the cooperative research project of the JRA-55 long-term reanalysis by the Japan Meteorological Agency (JMA) and the Central Research Institute of Electric Power Industry (CRIEPI). Part of this work was carried out as the commissioned work (0155-0133 Promotion of observation and analysis of radio wave propagation) of the Ministry of Internal Affairs and Communications, Japan.

\section{Authors' contributions}

HS proposed the topic and analyzed the data of GAIA simulation and foEs data. HS, HJ, YM, and HF developed the GAIA model. HJ and YM carried out simulation and created the simulation database. CT developed the real-time GAIA system and constructed the database. All authors read and approved the final manuscript.

\section{Funding}

This work was supported by JSPS KAKENHI Grant Numbers JP15H03733 and JP15H05815. Part of this work was also supported by the commissioned work (0155-0133 Promotion of observation and analysis of radio wave propagation) of the Ministry of Internal Affairs and Communications, Japan.

\section{Availability of data and materials}

All the ionosonde data used in this study are available from website (http:// wdc.nict.go.jp/IONO/index_E.html). GAIA simulation data are available upon request to H. Jin (jin@nict.go.jp).

\section{Ethics approval and consent to participate}

Not applicable. 


\section{Consent for publication}

Not applicable.

\section{Competing interests}

The authors declare that they have no competing interests.

\section{Author details}

${ }^{1}$ Space Environment Laboratory, Applied Electromagnetic Research Institute, National Institute of Information and Communications Technology, Tokyo 184-8795, Japan. ${ }^{2}$ Department of Earth and Planetary Sciences, Kyushu University, Fukuoka 819-0395, Japan. ${ }^{3}$ Faculty of Science and Technology, Seikei University, Tokyo 180-8633, Japan.

\section{Received: 19 July 2020 Accepted: 3 December 2020}

Published online: 27 January 2021

\section{References}

Andoh S, Saito A, Shinagawa H, Ejiri KM (2020) First simulations of day-to-day variability of mid-latitude sporadic E layer structures. Earth Planets Space 72:165. https://doi.org/10.1186/s40623-020-01299-8

Arras C, Wickert J, Beyerle G, Heise S, Schmidt T, Jacobi C (2008) A global climatology of ionospheric irregularities derived from GPS radio occultation. Geophys Res Lett 35:L14809. https://doi.org/10.1029/2008GL034158

Campbell-Brown MD, Jones J (2006) Annual variation of sporadic radar meteor rates. Mon Not R Astron Soc. https://doi.org/10.111 1/j.1365-2966.2005.09974.x

Christakis N, Haldoupis C, Zhou Q, Meek C (2009) Seasonal variability and descent of mid-latitude sporadic E layers at Arecibo. Ann Geophys 27:923-931. https://doi.org/10.5194/angeo-27-923-2009

Chu X, Yu Z (2017) Formation mechanisms of neutral Fe layers in the thermosphere at Antarctica studied with a thermosphere-ionosphere $\mathrm{Fe} /$ $\mathrm{Fe}^{+}$(TIFe) model. J Geophys Res Space Phys 122:6812-6848. https://doi. org/10.1002/2016JA023773

Chu YH, Brahmanandam PS, Wang CY, Su CL, Kuong RM (2011) Coordinated observations of sporadic E layer made with Chung-Li 30MHz radar, ionosonde and FORMOSAT-3/COSMIC satellite. J Atmos Sol Terr Phys 73:883-894. https://doi.org/10.1016/j.jastp.2010.10.004

Chu YH, Wang CY, Wu KH, Chen KT, Tzeng KJ, Su CL, Feng W, Plane JMC (2014) Morphology of sporadic E layer retrieved from COSMIC GPS radio occultation measurements: Wind shear theory examination. J Geophys Res Space Physics 119:2117-2136. https://doi.org/10.1002/2013JA019437

Codrescu MV, Negrea C, Fedrizzi M, Fuller-Rowell TJ, Dobin A, Jakowsky N, Khalsa H, Matsuo T, Maruyama N (2012) A real-time run of the Coupled Thermosphere lonosphere Plasmasphere Electrodynamics (CTIPe) model. Space Weather 10:S02001. https://doi.org/10.1029/2011SW000736

Drob DP, Emmert JT, Crowley G, Picone JM, Shepherd GG, Skinner W, Hays P, Niciejewski RJ, Larsen M, She CY, Meriwether JW, Hernandez G, Jarvis MJ, Sipler DP, Tepley CA, O'Brien MS, Bowman JR, Wu Q, Murayama Y, Kawamura S, Reid IM, Vincent RA (2008) An empirical model of the Earth's horizontal wind fields: HWM07. J Geophys Res 113:A12304. https://doi. org/10.1029/2008JA013668

Earle GD, Bishop RL, Zhou QH, Wallace SP (1998) A comparative study of insitu and remote intermediate layer measurements against wind model predictions of vertical ion drift. J Atmos Sol-Terr Phys 60:1313-1330

Feng W, Marsh DR, Chipperfield MP, Janches D, Hoffner J, Yi F, Plane JMC (2013) A global atmospheric model of meteoric iron. J Geophys Res Atmos 118:9456-9474. https://doi.org/10.1002/jgrd.50708

Fentzke JT, Janches D (2008) A semi-empirical model of the contribution from sporadic meteoroid sources on the meteor input function in the MLT observed at Arecibo. J Geophys Res 113:A03304. https://doi. org/10.1029/2007JA012531

Fujiwara H, Miyoshi Y (2006) Characteristics of the large-scale traveling atmospheric disturbances during geomagnetically quiet and disturbed periods simulated by a whole atmosphere general circulation model. Geophys Res Lett 33:L20108. https://doi.org/10.1029/2006GL027103

Haldoupis C (2012) Midlatitude sporadic E. A typical paradigm of atmosphere-ionosphere coupling. Space Sci Rev 168:441-461. https://doi. org/10.1007/s11214-011-9786-8
Haldoupis C, Meek C, Christakis N, Pancheva D, Bourdillon A (2006) lonogram height-time-intensity observations of descending sporadic E layers at mid-latitude. J Atmos Sol-Terr Phys 68:539-557. https://doi.org/10.1016/j. jastp.2005.03.020

Haldoupis C, Pancheva D, Singer W, Meek C, MacDougall J (2007) An explanation for the seasonal dependence of midlatitude sporadic E layers. J Geophys Res 112:A06315. https://doi.org/10.1029/2007JA012322

Harada Y, Kamahori H, Kobayashi C, Endo H, Kobayashi S, Ota Y, Onoda H, Onogi K, Miyaoka K, Takahashi K (2016) The JRA-55 Reanalysis: Representation of atmospheric circulation and climate variability. J Meteor Soc Japan 94:269-302. https://doi.org/10.2151/jmsj.2016-015

Hyvärinen O (2014) A probabilistic derivation of Heidke skill score. Weather Forecast 29:177-181. https://doi.org/10.1175/WAF-D-13-00103.1

Jin H, Miyoshi Y, Pancheva D, Mukhtarov P, Fujiwara H, Shinagawa H (2012) Response of migrating tides to the stratospheric sudden warming in 2009 and their effects on the ionosphere studied by a whole atmosphere-ionosphere model GAIA with COSMIC and TIMED/SABER observations. J Geophys Res 117:A10323. https://doi.org/10.1029/2012JA017650

Kato S, Aso T, Horiuchi T, Nakamura J, Matsuoka T (1972) Sporadic-E formation by wind shear, comparison between observation and theory. Radio Sci 7:359-362

Kobayashi S, Ota Y, Harada Y, Ebita A, Moriya M, Onoda H, Onogi K, Kamahori H, Kobayashi C, Endo H, Miyaoka K, Takahashi K (2015) The JRA-55 Reanalysis: General specifications and basic characteristics. J Meteor Soc Japan 93:5-48. https://doi.org/10.2151/jmsj.2015-001

Larsen MF (2002) Winds and shears in the mesosphere and lower thermosphere: Results from four decades of chemical release wind measurements. J Geophys Res 107(A8):1215. https://doi.org/10.1029/2001JA0002 18

Larsen MF, Yamamoto M, Fukao S, Tsunoda RT, Saito A (2005) Observations of neutral winds, wind shears, and wave structure during a sporadic-E/QP event. Ann Geophys 23:2369-2375

Liu HL, Bardeen CG, Foster BT, Lauritzen P, Liu J, Lu G, Marsh DR, Maute A, Mclnerney JM, Pedatella NM, Qian L, Richmond AD, Roble RG, Solomon SC, Vitt FM, Wang W (2018) Development and validation of the Whole Atmosphere Community Climate Model with thermosphere and ionosphere extension (WACCM-X 2.0). J Adv Model Earth Syst 10:381-402. https://doi. org/10.1002/2017MS001232

MacLeod MA (1966) Sporadic ETheory. I Collision-geomagnetic equilibrium. J Atmos Sci 23:96-109

Maksyutin SV, Sherstyukov ON, Fahrutdinova AN (2001) Dependence of sporadic-E layer and lower thermosphere dynamics on solar activity. Adv Space Res 27(6-7):1265-1270

Mathews JD (1998) Sporadic E: current views and recent progress. J Atmos Sol-Terr Phys 60:413-435

Mathews JD, Bekeny FS (1979) Upper atmosphere tides and the vertical motion of ionospheric sporadic layers at Arecibo. J Geophys Res $84: 2743-2750$

Miyoshi Y, Fujiwara H, Jin H, Shinagawa H, Liu H (2012) Numerical simulation of the equatorial wind jet in the thermosphere. J Geophys Res 117:A03309. https://doi.org/10.1029/2011JA017373

Nygrén T, Lanchester BS, Huuskonen A, Jalonen L, Turunen T, Rishbeth H, van Eyken AP (1990) Interference of tidal and gravity waves in the ionosphere and an associated sporadic E layer. J Atmos Terr Phys 52:609-623

Pezzopane M, Pignalberi A, Pietrella M (2015) On the influence of solar activity on the mid-latitude sporadic E layer. J Space Weather Space Clim 5:A31. https://doi.org/10.1051/swsc/2015031

Pezzopane M, Pignalberi A, Pietrella M (2016) On the solar cycle dependence of the amplitude modulation characterizing the mid-latitude sporadic E layer diurnal periodicity. J Atmos Sol-Terr Phys 137:29-35. https://doi. org/10.1016/j.jastp.2015.11.010

Prasad SNVS, Prasad DSSWD, Venkatesh K, Niranjan K, Rama Rao PVS (2012) Diurnal and seasonal variations in sporadic E-layer (Es layer) occurrences over equatorial, low and mid latitude stations - a comparative study. Ind J Radio Space Phys 41:26-38

Qian L, Burns AG, Emery BA, Foster B, Lu G, Maute A, Richmond AD, Roble RG, Solomon SC, Wang W (2014) The NCAR TIE-GCM: A community model of the coupled thermosphere/ionosphere system. In: Huba J, Schunk R, Khazanov G (eds) Modeling the ionosphere-thermosphere system, AGU Geophysical Monograph Series vol 201, pp 73-83. https://doi. org/10.1029/2012GM001297 
Sakai J, Hosokawa K, Tomizawa I, Saito S (2019) A statistical study of anomalous VHF propagation due to the sporadic-E layer in the air-navigation band. Radio Sci 54:426-439. https://doi.org/10.1029/2018RS006781

Shinagawa H, Miyoshi Y, Jin H, Fujiwara H (2017) Global distribution of neutral wind shear associated with sporadic E layers derived from GAIA. J Geophys Res Space Phys. https://doi.org/10.1002/2016JA023778

Singer W, von Zahn U, Weiss J (2004) Diurnal and annual variations of meteor rates at the arctic circle. Atmos Chem Phys 4:1355-1363

Tao C, Jin H, Miyoshi Y, Shinagawa H, Fujiwara H, Nishioka M, Ishii M (2020) Numerical Forecast of the Upper Atmosphere and lonosphere using GAIA. Earth Planets Space 72:178. https://doi.org/10.1186/s40623-02001307-x

Whitehead JD (1989) Recent work on mid-latitude and equatorial sporadic-E. J Atmos Terr Phys 51:40-424

Wu DL, Ao CO, Hajj GA, Juarez MT, Mannucci AJ (2005) Sporadic E morphology from GPS-CHAMP radio occultation. J Geophys Res 110:A01306. https:// doi.org/10.1029/2004JA010701
Yeh WH, Liu JY, Huang CY, Chen SP (2014) Explanation of the sporadic-E layer formation by comparing FORMOSAT-3/COSMIC data with meteor and wind shear information. J Geophys Res Atmos 119:4568-4579. https:// doi.org/10.1002/2013JD020798

Yuan T, Fish C, Sojka J, Rice D, Taylor MJ, Mitchell NJ (2013) Coordinated investigation of summer time mid-latitude descending E layer (Es) perturbations using Na lidar, ionosonde, and meteor wind radar observations over Logan, Utah (41.7 N, 111.8 W). J Geophys Res Atmos 118:1734-1746. https://doi.org/10.1029/2012JD017845

\section{Publisher's Note}

Springer Nature remains neutral with regard to jurisdictional claims in published maps and institutional affiliations.

\section{Submit your manuscript to a SpringerOpen ${ }^{\odot}$ journal and benefit from:}

- Convenient online submission

- Rigorous peer review

- Open access: articles freely available online

- High visibility within the field

- Retaining the copyright to your article

Submit your next manuscript at $\gg$ springeropen.com 